\title{
An illustrated Textbook Ear, Nose and Throat and Head and Neck Surgery
}

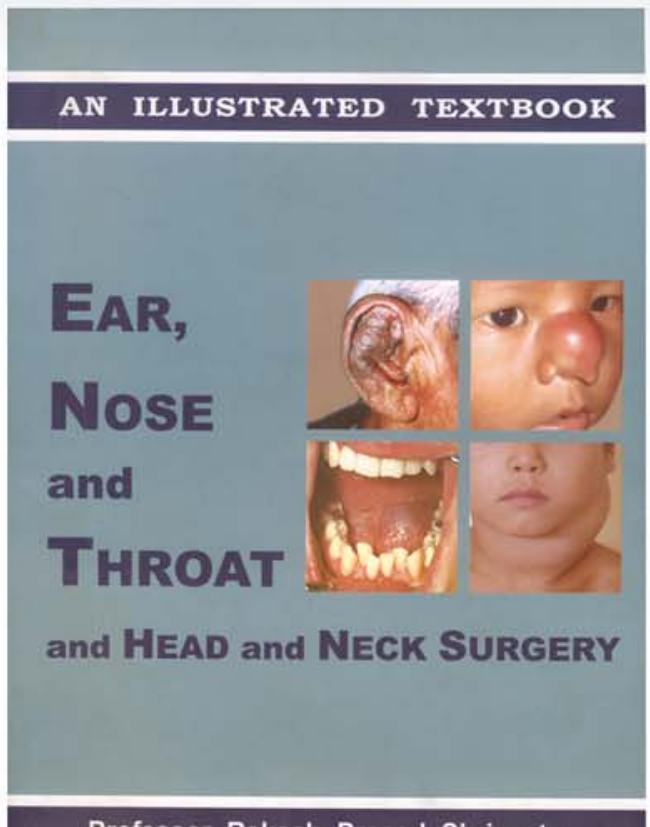

This is a concise textbook on ENT Head and Neck Surgery for the undergraduate medical students. The author is an eminent professor who has been in the teaching profession for more than 26 years. Professor Shrivastav has conveyed his experiences and expertise on the subject through this book. The book itself has 202 pages and is slightly smaller in size than A4 size paper. It is divided into five sections - the ear, the nose, the throat and Head and Neck and the related topic and lastly the index. All the 59 chapters are well written, have good illustrations with highlighted key points at the end of each chapter. The knowledge imparted through topics seems to be adequate for the undergraduates. There are hardly any grammatical mistakes as this book comes from "Mr Perfection", and the printing is superb. Overall the book is a good buy for money. However, there are few shortcomings which can be improved in the next edition. Practice of medicine should be evidence based as far as possible. The controversial matter should be mentioned e.g. the etiology of nasal polyp, treatment of idiopathic sensorineural hearing loss. A reference for further reading at the end of a chapter will be very useful. 